\title{
A Coherent System for Manitoba
}

\author{
EDWARD F. SHEFFIELD*
}

Report of the Task Force on Post-Secondary Education in Manitoba (Michael Oliver, Chairman). Winnipeg: Queen's Printer, 1973.

The emphasis of this Report is on the creation of a coherent system of post-secondary education in Manitoba, including the universities, the community colleges, and a new regional organization for non-institutional education. In order that this system should be effectively planned and coordinated, it is proposed that it be managed by an "autonomous" Commission on Post-Secondary Education with some advisory and many executive powers. To assure equality of opportunity and an increase in the role of the public in post-secondary education, a new instrument is proposed which would encourage local districts to take the initiative in meeting their own needs-to a large extent by using their own talents, though with support from the central government. Like most other recent reports on higher education, the theme of lifelong learning is central, as is the problem of financing. Of special interest in connection with the proposals for financing universities and colleges is the Task Force's proposal that the current formula for the allocation of operating funds on the basis of weighted student numbers should be replaced by assessment of institutional need in nine budget categories, only one of which (academic costs) would be based on student enrolment. In a sense, this would amount to a compromise between line-by-line budgeting and formula-based block financing.

The Task Force first attempts an analysis of the needs of the Seventies which it believes are different from those of the Sixties. It is in this connection that it states its objectives for the provincial system of post-secondary education. The first is equality of opportunity, with accessibility for everyone to an appropriate part of the system. In stating its objective, an increased public role in post-secondary education, the Task Force argues that the system should be characterized by openness, accountability and participation. There follows discussion of each of the three main elements of the proposed system.

Manitoba, a province of about a million people, has three universities, one large and two small. The Task Force sees no need for the creation of additional universities in the foreseeable future, but does recommend the addition of an External Studies Evaluation Board with power to grant degrees to people who, on examination, are found to have met degree standards. It is suggested that the University of Manitoba should continue

* Edward F. Sheffield, Professor of Higher Education, University of Toronto. 
with its provision of undergraduate and graduate studies and research, including professional education; that the University of Winnipeg should be primarily an undergraduate teaching institution, but with limited extension to the master's level; and that Brandon University should confine its activities to the teaching of undergraduates. In all cases, however, it is argued that professors should be involved in research as well as in teaching. This particular point of view runs counter to the opinion recently expressed in many quarters: that some members of university faculties should be discouraged from undertaking frontier research though all should engage in reflective inquiry. (The reader will recognize this as a distinction made by Louis-Phillipe Bonneau and J.A. Corry in their recent report, Quest for the Optimum.) The universities are congratulated on their service to society although it is pointed out that there is need to improve their response to disadvantaged groups, including, for example, women and native people.

Turning to the community colleges, the Task Force notes that there are also three of them, again one large and two small. As in the case of the universities, it is suggested that no more institutional provisions of this kind will be needed in the immediate future, in spite of the fact that it is expected that enrolment in the colleges is likely to grow more rapidly than in the universities. Although the colleges are given credit for valiant effort, it is noted that they suffer from overcentralized control, the dominance of programmes sponsored and paid for by Canada Manpower, lack of participation by teaching staff and students in decision-making and, as a consequence of all of these problems, low faculty morale. The Task Force hopes that the colleges may be preserved from modeling themselves on the universities but does advocate the establishment of equivalence between college and university courses so that transfer from one type of institution to the other may be facilitated. Indeed, it recommends that discussion of the equivalence of credits should be initiated soon. In my view, it probably would be more profitable to lay the stress on quality of performance rather than quantity of credits, and on general comparisons between programmes rather than specific comparisons between individual courses.

In order to bring post-secondary education to the people outside the three centres in which there are colleges or universities (Winnipeg, Brandon and The Pas) the Task Force considered the desirability of recommending an organization on the model of the British Open University. This they rejected in favour of a "less expensive, more personal" plan by which the initiative for courses, whether for credit or not, would be taken by committees at the local (District) level. These, it is suggested, might on occasion group themselves together as Areas (several adjacent Districts) and on a broad scale the province would be sub-divided into six Regions, one of them francophone. The Task Force leads one to imagine the situation in which a person in a small community or on a reservation might express to his District committee an interest in learning about some topic or other. The District committee would then discover whether others had a similar interest and whether a suitable teacher could be found locally. If not, it might be that the nearest university or community college could be invited to sell the required instructional package to the District.

As the picture unfolds one gets the impression that there is potential for a great deal of such voluntarily initiated and organized learning activity throughout the province although the Task Force is careful not to suggest that everyone is just aching to take a 
course of some kind. Needless to say, most of the learning activity which might result from such a programme would not lead to credits for degrees or diplomas, although some of it might. It is clear that a great deal of reliance would be placed upon the enthusiasm of volunteers. One may be pardoned for wondering whether enthusiasm is likely to have sufficient continuity to sustain such a programme of public adult education for long. This kind of grass roots educational activity has been hinted at or proposed with some frequency in recent years. Are there examples of its successful execution? (A few days after I wrote that query I read of a programme much like that proposed for Manitoba-that of the Community College of Vermont, begun in 1970. It is described in the Fall 1973 issue of the Carnegie Quarterly.)

In its discussion of the major problem areas in post-secondary education, the Task Force includes a chapter on learning and teaching. The emphasis here is on support and encouragement by colleges and universities for changes initiated by students and teachers. It is recommended that each institution establish an Educational Development Fund to support teaching experiments, and also that there be a provincial Centre for Educational Development. A good case is made for a review of the current modes of evaluating students' learning and for the introduction of a systematic evaluation of teaching. According to the Task Force the main object of the former should be to help students learn, the latter to help teachers teach. It is recommended that there be in-service training in pedagogy for all teachers in the community colleges, that courses on teaching be available on a voluntary basis for university faculty, and that such courses be required for graduate students who serve as teaching assistants.

Concerning the desirability of having students involved in the evaluation of teaching, the Task Force repeats some myths. "Students may not be the best judges of teaching," observes the Task Force. "They may respond to a facile purveyor of superficialities more than to the teacher who conscientiously digs into the tough corners of his subject." (Most research evidence is that this is not so.) Later comes this observation: "Graduates who have been out of university for two or three years frequently have a different perspective on the teaching abilities of their professors than when they were taking their courses." (This seems not to be so either.)

On the question of the relationships between secondary and post-secondary education, the Task Force recognizes the influence of the university on curriculum in the high school, although many changes have lessened this influence in the last decade or so. Wisely, particular attention is paid to the problem of articulating the secondary and post-secondary parts of the educational system, for it is at this point of passage that many of the problems are to be found. In order to reduce the incidence of such problems, the Task Force recommends that admission to post-secondary education be on a subject basis. To give effect to this recommendation, it is suggested that some senior high school students be given the opportunity to take university-level courses in the final years of their high school programme, and also that the universities be encouraged to continue to provide make-up courses for those who have been admitted with deficiency in subject-matter background in certain fields.

The chapter on participation, accountability and governance dwells particularly on the patterns of internal government of universities and colleges. Retention of a bicameral 
form of university government is recommended, together with provisions for effective liaison between senates and boards of governors. For the colleges the Task Force recommends a unicameral form of board to take the place of the currently ineffective advisory bodies which, according to the Task Force, have been largely superseded by direct negotiations between college principals and officials of the Department of Colleges and Universities Affairs.

With respect to the organization of the post-secondary education system of Manitoba, it is suggested that there be a Department of Post-Secondary Education to take the place of the existing Department of Colleges and Universities Affairs, that the Minister should deal primarily with basic matters of post-secondary education policy in relation to other broad governmental policies, and that most of the responsibility for running the system should be delegated to a Commission on Post-Secondary Education. This would operate in much the same way as the province's Universities Grants Commission now operates, although it would have jurisdiction over the whole of the post-secondary system rather than over the universities alone. The proposed Commission would be made up of three divisions, one concerned with universities, one with community colleges, and the third with the new regional organization. The Commission would recommend to the Minister the global sum of money needed for each of the three divisions, but the division concerned would decide how to allocate the funds among the component parts of its area. The model proposed for Manitoba seems to be not unlike that recently proposed for Ontario, and also rather like the one from which Alberta has just departed. (In Alberta a government Department of Advanced Education has assumed the functions which for seven years had been performed by semi-autonomous university and college commissions.)

In connection with its discussion of planning for post-secondary education, the Task Force raises what is probably the key question concerning the relation between government and institutions of higher education: To what extent can the government's power be delegated to a body like the proposed Commission on Post-Secondary Education? It is pointed out that in the proposed organization of the system the government would be assigned no role in planning post-secondary education except for membership by the Deputy Minister of Post-Secondary Education on the Board of the Commission. The question is asked how the Minister is going to inform and account to the Legislature. Then the reply:

We propose that the Minister carry out these fundamental responsibilities without exercising the powers that normally go along with them. This is the present situation, by and large, with respect to the universities but ministerial powers over the community colleges are now much more direct.

There are plenty of precedents for Ministerial responsibility with a minimum of power to make detailed regulations. Ministers who report to the legislative body, federal or provincial, for Crown Corporations, Boards, and Commissions are frequently placed in this position. At the federal level, housing and broadcasting are handled in this way. But none is as vital as education. We can only apply a principle of minimum direct ministerial power to post-secondary education if the system works as proposed, that is, with an effective participatory structure. Otherwise it would be unwise (and probably unrealistic as well) to propose the reduction of governmental power to plan and to allocate funds for specific 
activities. To justify its independence from direct control, the system as proposed will need to demonstrate not only its technical competence but its ability to set planning goals embodying public expectations and to carry out its plans in ways involving public participation.

One might wonder whether the Task Force has not provided in these paragraphs the kind of argument which will make it difficult for the Government to accept the recommendation regarding the "autonomy" of the proposed Commission on Post-Secondary Education. If the Government does accept this recommendation, the Commission will assume what the Task Force describes as a "new role"-that of coordination and planning for the system. It is notable, incidentally, that the Task Force did not offer a master plan or blueprint for the system, but rather a plan for planning.

Finally and inevitably the Task Force deals with the financing of the system. After extensive consideration, it decided that it should recommend no substantial increase in tuition levels. It examined with care the student aid programme of the Province and recommends that it be somewhat liberalized, particularly with respect to the classification of students as independent from their parents. The chief element of this discussion of finances, however, has to do with the basis for distributing government grants to universities and colleges. The Task Force notes that in the present system of formula financing "student-program costs ... serve as a substitute measurement for all functions and costs of the university." It notes also that community college budgets are now prepared and scrutinized on a line-by-line basis as in other government departments. For both the universities and the colleges it is suggested that government grants be made to each institution on the basis of "specific allocations by budget category." The nine categories proposed are: first claims (e.g. debt service charges), maintenance expenditures, ancillary services, academic administration, administrative support services, research, academic costs, community service, and capital costs. The Task Force argues, with conviction, that only the category covering academic costs is really related directly to student numbers. It recommends, therefore, that a weighted enrolment formula be used only in connection with assessing the need for funds in that category. Presumably the University Division or the College Division of the Commission would assess in a more subjective way each institution's proposals for support in the other eight categories.

With respect to the report as a whole, one of the major difficulties is created by the decision taken by the Task Force to interpret the expression "post-secondary education" to comprise the education and training of people over sixteen years of age who are no longer in school, that is, after high school rather than after completion of high school. It deals, therefore, with what would be more easily understood if it were described as postsecondary and adult education. Others have tackled this problem by distinguishing between compulsory and post-compulsory education, or between compulsory and optional education. But none of these solutions is really satisfactory.

Jan Morgan, the editor, is to be complimented on the effective organization of the Report. In each part there is a definition of goals or objectives, a statement and discussion of the chief problems, and then proposed solutions and recommendations. The whole thing is done in a low key. Much use is made of the ideas of others (with acknowledgement in a general way, though not in particular). One notes, for example the indebtedness 
of the Task Force to ideas or practices currently to be found in Alberta, Saskatchewan, Ontario and Quebec. The fact that the Task Force began in February 1972 and presented its report in mid-1973 (although it was not published until December) must have created something of a record for speed.

The overall mood created is one of hope and optimism, but one senses that this may be a brave front. Between the lines one realizes that the story of things as they are in Manitoba is in many ways a sad story. One of the three universities is small and struggling; two of the three colleges are little more than trade schools; and the plight of the native people makes one's heart ache. The fact that the Task Force reveals a deep concern for people gives hope that improvement is possible. This is brought out effectively by the device of inserting scenarios at three points in the text. Each of these introduces real people meeting real problems in real settings.

One can be critical of three small matters. Although the seven members of the Task Force are named, the reader is not told anything about their roles in their communities. The list of references seems to have been put together with too little care: some of the documents referred to in footnotes do not appear in the list of references, and some authors' names are incorrect or lacking initials. Curiously, one has to read the text carefully to discover when the Report was published and one is not informed anywhere that the publisher is the Queen's Printer in Winnipeg. This information certainly ought to appear on the title page.

There have been enough provincial studies of systems of higher education in the last few years to offer one an opportunity to make comparisons. In the light of such comparisons, this Report stands up extremely well. Not only is it logically organized and sensibly argued, but also its proposals seem likely to be workable; indeed many of the problems of implementation are anticipated. 